\title{
Peer relations: The challenges of children with special needs
}

\author{
Elsa Marta Soares 1, Ana Maria Serrano 2 \\ 1 Polytechnic Institute of Leiria, Portugal \\ 2 University of Minho, Portugal
}

\section{Resumen}

Los niños con necesidades especiales, debido tanto a su mayor probabilidad de desarrollar una o varias alteraciones como a los obstáculos que pueden encontrar en su contexto, pueden ver comprometidas sus relaciones sociales. Esto puede tener consecuencias en el corto y en el largo plazo. Es por lo tanto esencial conocer los factores que pueden influir en el desarrollo de la competencia social de los niños con sus iguales. Solo entonces los profesionales podrán tener un rol activo en el incremento de la estimulación de dichas competencias. Esta revisión contempla las perspectivas de diferentes autores acerca del desarrollo social de los niños con sus iguales. Es en la convergencia de estas perspectivas en donde uno puede encontrar la complementariedad necesaria para comprender el dinamismo y las inter-relaciones características e inherentes a la competencia social.

Palabras clave: Competencia social; Interacción social; Necesidades especiales; Relación entre iguales.

\begin{abstract}
Children with special needs, due to the greater likelihood of developing a disorder in one or more areas of their development, and due to the obstacles they may find in the context, can have their social performance compromised, which can entail consequences in short and in long term. It is, therefore, essential to know the factors that may influence the development of their peer related social competence. Only then can the caregivers play an active role in order to increase the chances of stimulating these competencies. This review addresses the perspectives of different authors about the social development of children with their peers. It is at the convergence of each of these perspectives that one can find the complementarity needed to effectively understand the dynamism and the inter-relational characteristics inherent to social competence.

Keywords: Peer relations; Social competence; Social interaction; Special needs.
\end{abstract}

Correspondence with authors: elsa.soares@ipleiria.pt

Received 1 April. Accepted 29 May

Acknowledgments: To the Portuguese Foundation for Science and Technology - SFRH/BD/70351/2010 and to the European Social Fund. 


\section{Introduction}

There are several studies that underline the importance of social interaction with peers as a context in which the child learns more advanced ways of social competence (Brown, Odom, \& Conroy, 2001; Chen \& French, 2008; McEvoy, Odom, \& McConnell, 1992). It is in these interactional situations that children find a secure environment and an abundance of natural opportunities that allow them to practice their social knowledge, to experience the positive or negative effects of using certain types of strategies in specific situations and, consequently, to enhance their level of social skills (Manz \& McWayne, 2004; Tanta, Deitz, White, \& Billingsley, 2005). Social performance influences the development of other areas, such as communication, language, cognition and emotion. In a parallel way, children's capacities in these areas are reflected on their social performance (Brown, et al., 2001; Guralnick, Connor, Neville, \& Hammond, 2006).

All this reality, inherent to the child, can only be understood if one also takes into account the two-way interactions that occur between the child and all of the factors, aspects, elements and processes of their immediate contexts - such as, for example, the relationship with their caregivers - or of the more distant contexts, that also indirectly influence the child - such as, for example, the professional environment that caregivers are experiencing (Bronfenbrenner, 1975; Sameroff \& Fiese, 2000; Sameroff \& Mackenzie, 2003).

This extensive and comprehensive perception allows us to realize that social competence, in peer relations, can be affected if there are also some disorders in these processes, elements or aspects (Guralnick, 2010). This is the reason why children with special needs $(\mathrm{SN})$ face more obstacles and challenges along the way, on the development of these competences (Guralnick, Hammond, \& Connor, 2006; Odom, McConnel, \& Brown, 2008). Only the adoption of a comprehensive and integrated approach allows us to realize that the strengthening of social skills is also dependent on the active role of the environment in increasing opportunities for interaction (Garbarino \& Ganzel, 2000; Meisels \& Burnett, 2000; Rantala, Uotinen, \& McWilliam, 2009).

The aim of this literature review is based on the understanding of the perspective of several authors relatively to the underlying thematic of peer related social competence, knowing that there are different theoretical views and it is possible to find, in most of them, focuses of convergence and of complementarity which clearly reflect 
that the teams working with children with SN and their families need to adopt a multidimensional and an inter-relational perspective.

\section{Theories of child development: the role of peers}

There are several theoretical currents that exploit the potential inherent processes/factors in child development. Despite the specific nature revealed by each of these theories, one can find, in many of them, common and complementary aspects.

Piaget's constructivist theory focuses essentially on human cognitive development $-\mathrm{a}$ sequence of stages, resulting from the assimilation and the accommodation processes arising from the relationship/action of the child on the environment. This theory highlights the importance of interactions with peers as the ideal situation to help the child to decentralize the thoughts from an essentially selfcentered perspective to another one that takes into consideration multiple perspectives (Lefrançois, 1995; Richmond, 1970; Tryphon \& Vonèche, 1996; Wozniak, 1996). In fact, it is in peer group that the child is confronted with those children who can accept or opposite opinions (Brown, Metz, \& Campione, 1996). The conflicts which emerge resulting from disagreements in the group create a disequilibrium which forces the child to make a cognitive adjustment which, from Piaget's point of view, emerges as the motto for child development (A. L. Brown, et al., 1996; Hartup, 2009; Siraj-Blatchford, 2004).

Despite the common aspects shared by Piaget's theory and Bandura's, the latter believes that cognitive changes are not restricted to the intra-psychological conflict and argues that if all cognitive development depended merely on the child's action on the surroundings, then this would be a very slow process, based on lengthy trial-error activities (Bandura, 1977, 1989). Generally speaking, Bandura (1977, 1989) regards development as a close interrelation between the child's biological factors and all the experiences that the environment provides. The child and the context establish a bidirectional relationship, a reciprocal determinism, given the mutual influence they exert over each other (Bandura, 1977, 1989).

He adds, thus, according to his socio-cognitive perspective, that apart from the learning that can occur through the direct action of the child on the environment, one also has to take into account the preponderant importance of the learning through observation (Bandura, 1977). This is perceived as one of the most powerful ways of 
learning, which allows the child to detect the surrounding models and learn with them, expanding, consequently, knowledge and competences (Bandura, 1977). In this sense, emerges the concept of vicarious learning which is related to the child's ability to observe others' behaviors and to realize, through their consequences - positive or negative - if these are behaviors that could be adopted, or not, in similar situations (Bandura, 1977). Bandura (1989) also underlines the importance of the perception that the child develops about the self considering the influence that can be exerted on the surrounding environment, i.e. the sense of self-efficacy. This determines the actions that are pursued by the child, the effort dedicated to them and the persistence in the presence of obstacles and of experiences of failure (Bandura, 1989).

Based on the fact that most social learning occurs within peer relations, Bandura highlights the role of those who are more experienced and competent, as being the potential models of effective thoughts and behaviors (Bandura, 1989). It is also in these interactional contexts that the child can develop self-knowledge concerning his(er) capabilities. Positive experiences are essential to the continuous increase of the sense of self-efficacy, which is consequently and positively reflected, in peer relations (Bandura, 1989).

According to Vygotsky (1994a), development results from the close interconnection between genetic and cultural factors. At the genetic level, he references the organic development and the consequent maturity of the child (Vygotsky, 1994a). In cultural terms, this author underlines the importance of the past and present history, which encompasses all abilities that humanity have been improving over time and with which the child is in contact, once (s)he is ideally, submerged in a social group (Brown, et al., 1996; MacNaughton, 2004; Vygotsky, 1978, 1994). Thus, in the cultural development area, the psychological and the social plans are stressed (Wertsch \& Tulviste, 1996). So the child's social competences within social interaction become, over time and through processes of internalization, part of his(er) independent repertoires (Brown, et al., 1996; Corsaro, 1993; Hartup, 2009; Martí, 1996; Vygotsky, 1978). He believes, therefore, that in social contexts, children can find proximal developmental zones and therefore it is in those contexts that the child would find the possibility of developing emerging capabilities through problem solving under the guidance of an adult or in collaboration with more capable peers (Brown, et al., 1996; 
Fleer, Anning, \& Cullen, 2004; Siraj-Blatchford, 2004; Vygotsky, 1978; Wertsch \& Tulviste, 1996).

To Tomasello \& Carpenter (2007), Vygotsky's perspective justifies, by itself, the uniqueness of human cognition, which relies not only on the individual mental power, but also on the ability of the human being to collaborate with others in collective activities and to learn from them and their artifacts. Tomasello (2000) develops, thus, his perspective around the processes of cultural transmission, stressing that these allow the child to learn with and through the skills and knowledge that others within his contexts have learned thus, saving him time and effort.

Cultural learning allows socio-genesis processes - processes that lead to the development of new practices or social artifacts and which always are the result of interaction processes with others (Tomasello, 2000). Social practices and artifacts accumulate changes over time which demonstrates that cultural evolution is cumulative (Tomasello, 2000). This feature ensures that the human cognitive development takes place in an onto genic environment of artifacts and new social practices that represent, in themselves, the collective wisdom of the entire social group, taking into account the whole cultural history - thus, emerging the concept of social cognition (Tomasello, 2000).

In this way, Tomasello (2000) gives continuity to Vygotsky's perspectives, saying that development of each human being takes place within the individual and the cultural contexts, therefore, it is the result of an interaction between the biological and the cultural heritage - model of dual heredity (Tomasello, 2000). As one would expect, these two contexts of development merge, since early ages and it is difficult to really distinguish between them in children's cognitive actions (Tomasello, 2000).

In the course of cultural learning, the child will use the perceptions about how other people apprehend him(er) - emotionally and conceptually - to categorize the self towards them. Internalizing the perspective of others contributes, in a particular way, to the formation of the child's self-concept (Tomasello, 2000).

It is about the age of 9 months, with the emergence of joint attention activities, highlighted by the child's first attempts to share attention and learn from and through the imitation that the emergence of the social and human cognitive capacity arises. This allows the child to identify him/herself with other people, to understand them as intentional agents and to realize the "what" and the "why?" of another person using that 
instrument or that symbol. Only this way, can the child actually start the journey in the trajectory of cultural learning (Tomasello, 2000, 2003; Tomasello \& Carpenter, 2007).

Sameroff (2010) puts the emphasis on the subject and on the environment. According to the transaction perspective, human development occurs through constant transactions between these two entities. He stresses that both have an equally important role in this process, influencing one another (Sameroff \& Fiese, 2000; Sameroff \& Mackenzie, 2003). It is considered that there is a transaction when the activity of one element has a qualitative and/or quantitative impact on activity of another (Sameroff \& Mackenzie, 2003). This two-way and interdependent transactions relationship between the subject and the various subsystems in which (s)he is integrated stresses the importance of a bio-ecological perspective of the human development, as advocated by Bronfenbrenner $(1975,1999)$.

Through this model. Bronfenbrenner $(1975,1986)$ has developed a comprehensive framework for the development of the child, taking into account the influence of the various contexts and the prediction of how these affect the child and how they affect each other. Bronfenbrenner $(1975,1986)$ also perspectives human development as the result of a set of interactions between the individual and the environment. The individual is an active being who acts on the environment, recreating it. In turn, the environment - which encompasses the immediate context, as well as various interrelationships between the various contexts - influences the development of the child through "powerful forces" (Bronfenbrenner, 1975, p. 15) that affect the child directly and indirectly (Bronfenbrenner, 1975). We realize, thus, the need to focus our attention on the development of the child, but also, and equally important, on his(er) ecology (Bronfenbrenner, 1975). According to his perspective, the developing child is at the centre of an ecological framework, in which (s)he is surrounded, on a first level, by the micro-system, then by the mesosystem, followed by the exosystem and, finally, by the macrosystem (Bronfenbrenner, 1975). All of these subsystems refer to contexts that influence the child more or less directly.

The microsystem corresponds to child's living and experiences in the immediate contexts, regarding activities, roles and relationships. The mesosystem concerns the interrelations that occur between two or more of these contexts,

In the exosystem, there is no direct involvement of the child. However, this subsystem plays an equally important role, since there are situations occurring within it 
that affect the microsystems, or which are affected by them, and that, consequently, affect the child's development (Bronfenbrenner, 1986, 1999; Portugal, 1992). Bronfenbrenner (1986) says that there are three exosystems that may affect the child's development, acting mainly at the level of the family processes, including the work of caregivers, their social networks, and the community's influence on the functioning of the family.

The macrosystem refers to a broader concept and not to a specific context. It, therefore, concerns values, cultural patterns, ways of being and acting of the society that affects everything that occurs and develops in the other contexts.

In this way, Bronfenbrenner (1999) highlights that the increasingly more complex reciprocal interaction processes between a developing active organism and the people, the objects and the symbols of the environment emerge as the main source of development. To be effective, the interaction must occur regularly and during extended periods of time, so that the process of complexity can occur. In his perspective, these maintained interactions in the immediate environment interaction are defined as proximal processes and can be detected in various activities, such as, for example, those which occur between the caregiver and the child and/or between the child and the peers (Bronfenbrenner, 1999).

The theoretical currents that have been explored demonstrate the inherent complexity of the process of human development and, consequently, of the acquisition of the necessary social skills for a positive social performance, which is in line with Mishall e Hojnoski's (2008) statement, "There is no clear and accepted definition of social development; there are, however, theories and methods that articulate multiple paths for the development and acquisition of social competence" (p. 119).

\section{Social competence in peer relations}

Despite the different aspects that are emphasized, all of the above theories value the role of peers in the development of the child. Indeed, the complexification of social skills is intrinsically connected to the opportunities for interaction with peers - perceived as central to development - as well as to the competence that the child reveals within the interaction (W. H. Brown, et al., 2001; Guralnick, 2006b).

In order to clarify which aspects and processes are related to the development and use of social skills in relationships with peers, Guralnick (1992, 1999, 2010) has 
been developing comprehensive conceptual models, which complement each other and are increasingly comprehensive. In his perspective, social competence is linked to the child's efficiency in achieving successfully and appropriately the interpersonal goals, through the influence of the other's behavior. In peers' interactional situations, those objectives arise, most often, in contexts of social tasks such as, for example, the challenge of peer group entry (Guralnick, 1999). These kind of situations arise the child's need to generate social strategies that are crucial to effectively and appropriately solve these tasks, i.e., to be socially competent. The adequacy and the effectiveness in the use of these social strategies reveal the social competence aspects in the relationships with peers, and it becomes clear that the continued use of less appropriate strategies will weaken the child's chances to access groups and peers (Beckman \& Lieber, 1992; Corsaro, 1993; Corsaro \& Eder, 1990; Guralnick, 1992; Odom, et al., 2008). Thus, social competence can be envisioned as a continuum, in which very competent children select effective and appropriate strategies, which allow them to be well accepted in the group and to cultivate reciprocal friendships, right from their preschool age (Odom, et al., 2008).

The contemporary models state that there are three basic processes - foundation processes (shared understanding and emotion regulation); socio-cognitive processes, and higher-order processes - which seem to act together, while the child selects the social strategy and that these processes are, in turn, influenced by a diverse set of factors (Guralnick, 2006a, 2006b, 2010).

Sharing a common knowledge with peers (shared understanding), about the scripts underlying play activities, roles, social rules and behavioral expectations associated with each interactional situation, allows the child to have a greater probability of applying the social strategies appropriated to each specific situation, when compared to those children less familiar with this kind of realities ((Furman \& Walden, 1990; Guralnick, 2010).

Considering emotional competence, there are three factors underlying it -emotional knowledge, emotional expressiveness, and self-regulation related to emotion - which are reflected clearly in the patterns of interaction that the child establishes with peers (Denham et al., 2003). In fact, the child's competence in terms of emotional knowledge, and consequent ability to identify and respond appropriately to the emotions 
of others, taking into account social expectations, will be a determining factor for the success in interactions with peers (Diamond, Hong, \& Baroody, 2008).

At the level of expressivity, children capable of displaying positive affection towards peers have more success in the different social tasks than those who choose another approach. In fact, reacting more appropriately contributes to fostering children's relationship with each other. The ability to recognize emotions in peers, or even to understand the emotional consequences that a specific interactional situation can cause on them, is decisive (Denham, et al., 2003).

For emotion-related self-regulation, capacities of temperamental self-regulation -also designated as effortful control -which allow the individual to inhibit an emotionally dominant response and/or to active other less dominant, but which is more effective to achieve interpersonal objectives, are essential (Eisenberg, Spinrad, \& Eggum, 2010; Guralnick, 2006b).. It is, therefore, the effortful control capabilities that allow the individual to divert the attention from a negative stimulus and to focus it on a positive one, inhibiting an inappropriate behavior and activating or carrying out a positive action (Eisenberg, et al., 2010). Thus, the effortful control capabilities contribute to the child's ability to flexibly adapt to challenging situations. Difficulties at this level may be the cause of problems of externalization - such as the tendency to aggressiveness and provocation - and of internalization - tendencies to depression, anxiety and isolation (Eisenberg, et al., 2010; Guralnick, 2006b). The difficulties of emotion-related self-regulation can compromise the child's ability to organize a behavioral adaptative pattern, in a given context (Guralnick, 2006b) and, thus, debilitating child's development and use of the social cognition involved in information processing, damaging the quality of interactions (Eisenberg, et al., 2010).

The role of emotion appears, in later models, increasingly embedded in all of the steps of the socio-cognitive processes, supported by physiological studies that demonstrate their mutual influence, and consequently making difficult the process of isolating cases whether it is pure emotion or pure cognition (Crick \& Dodge, 1994; Lemerise \& Arsenio, 2000). Faced with a social situation, the child is influenced by past experiences and by biologically determined capabilities that will guide all of the social information processing (Crick \& Dodge, 1994). Despite the sequential description of the various steps involved in this processing, Crick and Dodge (1994) argue that there is a constant feedback phenomena among them. It is considered, therefore, that the emotion 
-related to memories of past experiences, to events immediately preceding some social situation or to the actual course of the current social situation - has a direct influence on the codification, interpretation and mental representation of internal and external cues; the selection of a goal; the access or the construction of a social response; the decision of which social response to use -taking into account the assessment of the responses used in previous situations - and the behavioral achievement of the chosen social response.

Simultaneously, it is necessary to recognize the task; to form an organized, coherent and consistent frame of reference, essential for the child capability of persisting in pursuing goals, with the monitoring capacity and the use of previous feedback, which reports to the importance of the higher order processes (Guralnick, 2010).

As one can see, all these processes are strictly interconnected, so the socially competent behavior is dependent on a synchronous and harmonious integration - any failure in one of the processes may affect the other(s) and thus trigger a set of events that can lead to a less positive experience with the peers (Guralnick, 2010).

There is also another diverse set of factors which, in turn, influence the development and functioning of these processes and that, therefore, are also intrinsically linked to the development, integration and expression of social skills (Guralnick, 1992, 1999; Odom, McConnel, \& McEvoy, 1992).

In this sense, it is stated the evolution at the level of the communicative and linguistic skills, which is essential for the child ability for conveying and understanding increasingly complex messages (Hanson, 2007; Tomasello, 2000). However, communicative and linguistic disorders, depending on their degree of severity, may condition the child's interactions with peers and/or prevent the child from developing more complex interactions with them, concerning, for example, negotiation and intensification of pretend play (Brown, Odom, McConnell, \& Rathel, 2008; Chapman \& Snell, 2011; Odom, et al., 2008; Odom et al., 2007; Schneider \& Goldstein, 2008; Tomasello, 2000).

The same thing is true for cognition because progression, at this level, is directly related to memory, attention, speed of information processing mechanisms, inherent to the socio-cognitive, higher order, and shared understanding processes (Guralnick, 1999). 
The preponderant role (in the development of emotion - related self-regulation) of the closest caregivers with whom the child establishes direct relations and that, therefore, are constituent elements of the mycrosystem must be highlighted (Chen \& French, 2008; Denham, et al., 2003; Guralnick, 2006a; Guralnick, Connor, et al., 2006; Guralnick, Hammond, \& Connor, 2006; Odom, et al., 2008). The importance of the kind of reactions that caregivers have, when faced with the child's emotions; the way they themselves express their emotions in the family setting or towards the child and the fact that they speak openly, or not, about the emotion is highlighted (Chen \& French, 2008; Eisenberg, et al., 2010).

Sensible and responsive caregivers who help the child to deal with their negative emotions and to understand them; caregivers who establish secure relations with the child, who express positive emotions in the context of their home and naturally transmit them to the child; caregivers who model the appropriate and effective social strategies and that can be later transported by the child to the contexts of peer interactions (Guralnick, 2006b; Odom, et al., 1992) - and caregivers who discuss, clearly, emotions with the child, contribute for an evolution of self-regulation ability (Eisenberg, et al., 2010; Guralnick, Hammond, Connor, \& Neville, 2006; McCollum \& Ostrosky, 2008; Odom, et al., 2008).

In fact, the contemporary models stress the importance of family influences on social competence in peer relations (Guralnick, 2010; Guralnick, Connor, et al., 2006). Some familiar interaction patterns that have been associated with the development of children and that converge with the above-mentioned Bronfenbrenner's perspective $(1975,1999)$ are mentioned - the quality of the connection and of the caregiver-child exchanges; the social experiences that caregivers can offer children, with regard to increase and foster social networks, and the risk/protection factors of the families as regards, for example, the availability of financial resources, of social support and of mental and maternal health (Guralnick, 2006a, 2006b, 2011; Guralnick, Hammond, Connor, et al., 2006).

The secure connections with caregivers are mirrored, most often, in more friendly, enthusiastic children, with a greater degree of social sensitivity (Beckman \& Lieber, 1992). The type of relationship the child lays down with them will be the basis for what (s)he expects to succeed with all other social relationships that (s)he establishes (Guralnick, 1999; McCollum \& Ostrosky, 2008). 
In fact, at an early stage of development, children need external sources of control - such as caregivers - to learn to control themselves emotionally, and only in a later phase can they start to regulate themselves through intrinsic processes (Denham, et al., 2003; Eisenberg, et al., 2010) that allow children to be able to adapt and modify their emotions, by controlling them, in various social situations, even in the more intense ones. Children with high levels of emotion regulation are able to respond appropriately in social situations, even in the most difficult conflict ones. The ability to work positively around these situations allows children to maintain play, which affords them many opportunities to practice and refine these skills with their peers (Corsaro \& Eder, 1990; Diamond, et al., 2008).

Quality relationships with their siblings can also foster the development of child's social competence aspects, such as emotional understanding, and the conflict resolution. Siblings also arise as a potential gateway to interaction with other peers, in other contexts (McCollum \& Ostrosky, 2008).

\section{Social interaction with peers}

Exchanges among peers have unique characteristics and qualities (Beckman \& Lieber, 1992), being fundamental to human development in all areas (Chen \& French, 2008; Guralnick, 1999, 2010) Considering social skills, the pre-school years are a period of rapid growth with a concomitant expansion of the network of social contacts (Bracken \& Fischel, 2007; Guralnick, Connor, et al., 2006).

In the course of the interactions, peers gradually get to know each other (Chen \& French, 2008). As they interact, there emerges a shared set of meanings and values that define what is expected from social behavior in various activities (Chen \& French, 2008; Corsaro, 1993; Odom, Zercher, et al., 2007). Peer culture, thus, emerges, as essential to the process of socialization (Corsaro, 1993; Corsaro \& Eder, 1990; Odom, Zercher, et al., 2007). A child who knows peers in different contexts will participate in different peer cultures. Being accepted in a peer culture is a challenge for children and if they, for some reason, exhibit ways of being or behaviors that are divergent from the established culture - such as displaying unmatched behaviors, liking different toys, playing roles differently - they can compromise their access and participation in the culture, and even, in some situations, they risk being rejected (Corsaro \& Eder, 1990; Hanson, 2007). 
The positive moments of social interaction with peers, in different contexts, are thus valuable for learning and increasing social skills (W. H. Brown, et al., 2008; Diamond, et al., 2008; McCollum \& Ostrosky, 2008; Odom, 2005). In these interactional situations, the child finds several natural opportunities to develop an understanding of pro-social behaviors, and to regard the self and the others as beings who have similar and/or different cognitions and perspectives. - this awareness allows the child to regulate expectations about what can be expected of the various interactional situations (Guralnick, 2006b; Odom, et al., 2008). The child constantly faces new situations and problems that need to be solved and this requires the need of learning to be compassionate, to trust, to regulate emotionally, and to fulfill the social norms of the group (Odom, et al., 1992).

It is exactly in the context of peer group that the child finds the security needed to learn how to solve conflicts, how to manage situations of aggression and how to engage in competition, without becoming aggressive (Chen \& French, 2008; Odom, et al., 1992).

Confrontation with these constant challenges, that require an active role, enables the child to use acquired cognitive, linguistic, emotional and motor skills, and, at the same time, to complexify them so that (s)he can be able to meet the demands of the environment (W. H. Brown, et al., 2001). This complexification is also reflected in the increasing ability to collaborate in the organization and construction of cooperative play activities which are more and more cognitively complex and demanding regarding the ability to maintain it during large periods of time (Guralnick, Hammond, \& Connor, 2006).

It is also stated that children exhibit more complex levels of play when they are with familiar peers, than when they are alone, or with unfamiliar peers (Beckman \& Lieber, 1992). Interacting with younger peers encourages children's spirit of help, as opposed to the presence of older children which increases dependence and help behaviors (Beckman \& Lieber, 1992).

As a matter of fact, playing is essential for learning social skills, and also the ideal context for their implementation and refining (Beckman \& Lieber, 1992).

In general, children who direct positive interactions to their peers, who help, who play cooperatively, are more likely to receive positive responses from their peers (Diamond, et al., 2008; Missall \& Hojnoski, 2008). Social acceptance by peers is related 
to how much they enjoy playing with the child, with his(er) ability to play positively, and with the presence of, at least, one mutual friend (Odom, Zercher, et al., 2007).

One realizes, therefore, that children with higher levels of pro-sociability can develop more mutual relationships and are more accepted by the others (Missall \& Hojnoski, 2008). Active social participation emerges as a means to facilitate the development of interpersonal systems of support, an important help to overcome psycho-emotional difficulties, particularly in adverse circumstances (Chen \& French, 2008).

Children who tend to be rejected are usually described by their peers as children who don't like to play, who show a tendency towards less positive interactions, with little communicative effectiveness and with difficulty to interact appropriately and continuously (Odom, Zercher, et al., 2007). The involvement in negative, limited and/or inappropriate interactions is closely related to the risk of affecting peer relationships, factor that must be valued, since early patterns of interaction emerge as the basis of later standards of behavior, which, if persisting, may have future consequences for the child (W. H. Brown, et al., 2008; Diamond, et al., 2008; Missall \& Hojnoski, 2008).

Children who are loved by their peers have a greater tendency to continue to receive positive affection as they become older, unlike children with a higher probability of rejection (Diamond, et al., 2008). We realize, thus, that children with friendship relations share a greater level of social satisfaction and reveal a greater ease in their adjustment to school, when compared to those who feel more alone (Diamond, et al., 2008).

Peer group entry, maintaining play and conflict resolution, emerge as three essential social tasks (Guralnick, 2010; Guralnick, Hammond, \& Connor, 2006). The child who tries to enter the peer group in a friendly way - through the use of social actions and questions - showing understanding and compliance with the current play framework, balancing his(er) wants and needs with those of peers, in order to establish a reciprocal and mutually rewarding relationship, can more easily achieve this goal, than the child who exhibits a more controlling behavior and tries to direct the attention of the group to him/herself (Diamond, et al., 2008). If a child does not take into consideration the perspective of others, the peer related goals can be jeopardized. 


\section{Social interaction of children with $\mathrm{SN}$}

Much bibliography states that children with SN have a higher tendency to exhibit difficulties in the interactions with their peers, given the constraints that they may face in the acquisition and learning of social skills - they demonstrate a greater probability of disorder of one, or more, of the factors and/or processes that have been mentioned as being critical for the development of social skills (W. H. Brown, et al., 2008; Guralnick, 1999, 2011; Guralnick, Connor, Hammond, Gottman, \& Kinnish, 1996; Guralnick, Connor, et al., 2006; McCollum \& Ostrosky, 2008; Odom, 2005; Odom, et al., 2008; Odom, et al., 1992).

The convergence of these factors can impact, consequently, all of the social performance of children with $\mathrm{SN}$, which is reflected in several aspects of their social interaction with peers. They are, thus, children who, as a general rule, are less effective in obtaining responses from their peers, when they suggest to them some kind of social proposal (Guralnick, 1999), which can also be related to their greater propensity for being less directive in their approaches (Guralnick, Connor, et al., 2006; Guralnick, Hammond, \& Connor, 2006). To these difficulties in initiating interactions, we must add up a tendency towards a lower response frequency and/or inappropriately response to peers' initiations (Odom, et al., 2008; Tanta, et al., 2005). Consequently, there is a lower probability of being chosen by their peers as play partners (Beckman \& Lieber, 1992). In fact, the group interaction situations are a real challenge for children with SN. For them, the social interactions negotiation is easier when they meet in dyad, because they are faced with fewer requirements, concerning complexity and coordination (Beckman \& Lieber, 1992). Thus, unlike peers without SN, who engage in activities that require high levels of communicative and social competence, such as the game with rules and the dramatic play, these children choose, preferentially, activities that require essentially motor skills (Odom, Brown, Schwartz, Zercher, \& Sandall, 2007; Sainato, Jung, Salmon, \& Axe, 2008)

Despite the beneficial consequences that could result from a constant interaction with peers without SN, children with $\mathrm{SN}$ seek, more frequently, peers with similar social skills to interact (Beckman \& Lieber, 1992). In turn, some of the children with SN have a greater tendency to address themselves, preferably, to adults, which can be related to being rejected and/or receiving more support from them (Odom, Brown, et al., 2007; Odom, Zercher, et al., 2007). 
The difficulties experienced by these children in their interaction with peers, from such an early stage, with the resulting experiences stemming therefrom, which are often negative, can be reflected in their quality of life in the long run, because they provide a difficult developmental pathway in the context of interpersonal relationships (Diamond, et al., 2008; Guralnick, 2006b, 2011; Guralnick, Connor, et al., 2006; Odom, et al., 2008).

As a matter of fact, the studies based on sociometric measures, concerning the opinions of the peers, reflect the idea that these children are less accepted, that they form more superficial relationships, and that they have fewer mutual friendships (Guralnick, 1992, 1999, 2010; Guralnick, Connor, et al., 2006; Odom, 2005; Odom, Zercher, et al., 2007). They are, therefore, submerged in a set of contextual and individual factors that influence their level of generalization of social strategies (Beckman \& Lieber, 1992).

At the cognitive level, there may be a jeopardy that makes difficult the appropriate processing of social information, the quick localization of complex stimuli, in the contexts of interaction, as well as the codification of social cues (Guralnick, 1992; Guralnick, Connor, et al., 2006).

Similarly, these are children that have a higher frequency of behavioral problems, related to disturbances of internalization and externalization processes, which, consequently, are caused by their difficulties with the management of emotion related self-regulation strategies (Guralnick, 2006b; Guralnick, et al., 1996).

In the context of the family, we must refer the stress that can be associated with the birth and with the characteristics of a child with SN (Guralnick, 2006a). This stress can influence the quality of caregiver-child interaction concerning the involvement, reciprocity, synchronicity and control (Guralnick, 2006a, 2006b). The new family dynamics, which often is created to fulfill the needs of the child, and that, in most cases, leads families to gradually grow apart from the activities of their community and of their extended family, is also a stress factor that, concomitantly, reduces the child's chances to relate with others (Guralnick, 2006a, 2006b). Finding opportunities for the child to play with other children emerges as a real challenge to these families (Guralnick, 2006a, 2006b). All these factors may, through transactional processes, lead to influences on the child (Guralnick, 2006b; Guralnick, Hammond, Connor, et al., 2006). 
Despite all of these adversities, the crucial role of parents in promoting social skills continues to be highlighted (Mahoney \& Nam, 2011; McCollum \& Ostrosky, 2008). In the context of peer relations, children are faced with a great unpredictability, with a greater complexity and with a smaller trend on the part of the peers to adapt themselves to the particular characteristics of these children (McCollum \& Ostrosky, 2008). Parents, on their turn and conversely, are able to adapt themselves better to these characteristics and, through a direct and/or indirect support, can create the necessary conditions for the child to improve and learn more complex social skills (McCollum \& Ostrosky, 2008).

Children with SN exhibit, often, linguistic limitations which influences their interaction with peers, at various levels (Guralnick, et al., 1996; Hanson, 2007). The child may have difficulties understanding what peers say and, consequently, the child's behavior may differ from what (s)he/ was asked or suggested to do (Guralnick, et al., 1996). They can, at the same time, present difficulties or unusual behaviors in their communication and/or in their linguistic expression (Odom, Zercher, et al., 2007). They may, thus, use ways considered atypical to communicate, for example, their desire to engage in some activity, which their peers may be unable to interpret (Odom, Zercher, et al., 2007). We can also see the absence or the production of a small number of words, or the difficulty in structuring simple and/or complex speech (Guralnick, et al., 1996), constraints that interfere with the ability of the child to monitor the increasingly complex play activities and that can lead him/her to avoid any kind of verbal interaction (Guralnick, et al., 1996). Thus these constraints limit the child's linguistic expertise with peers and prevent the learning from more evolved linguistic forms (Diamond, et al., 2008).

If roles and social rules must be learned within a context, if a repeated sharing of the play themes is necessary, in order to be expanded and to incorporate more social and cognitive variations, the constraints inherent to the social development of children with SN, considering all that has been stated, become clear (Guralnick, 1999). Actually we confirm that the social skills deficit leads to a reduction of opportunities for interaction with peers, which, in turn, prevents them from being able to evolve in that area (Odom, 2005; Odom, et al., 1992). Besides this, we must continue to emphasize the crucial role of the context and how we treat these children, i.e., as capable creating positive expectations about their competencies (Dunst, Trivette, Raab, \& Masiello, 2008). 
Children with SN, with moderate delays, reveal major difficulties regarding the social tasks already mentioned (peer group entry, maintaining play and conflict resolution) (Guralnick, 2011).

In peer group entry we verify that they exhibit a greater tendency towards the use of more intrusive and disruptive interaction styles, with difficulty in managing the different strategies. They demonstrate less use of emotion regulation strategies, when compared to children without SN. This may condition their access, even in the simplest situations of social interaction (Guralnick, Hammond, Connor, et al., 2006; Hanson, 2007; Odom, 2005). Thus, instead of choosing a direct involvement in activities already taking place, some children with SN choose to observe, to follow or to imitate play activities of their peers (Odom, Zercher, et al., 2007).

They are more susceptible to changes in the environment of the play - such as the change of the playmates - that often lead them to disrupt the activity (Guralnick, 1999; Guralnick, Connor, et al., 2006). When involved in conflicts, they exhibit less appropriate standards for solving them (Guralnick, Connor, et al., 2006), evidencing a greater use of negative strategies, or the absence of conciliatory strategies (Guralnick, 1999) -which, often, results from an inappropriate interpretation of the actions of others -sometimes peers address the child with a positive intention and the child interprets it in an opposite way (Odom, Zercher, et al., 2007).

It should be noted, however, that the group of children with $\mathrm{SN}$ also covers those children that present lighter difficulties and, therefore, have a greater likelihood of being accepted by their peers. That is what happens with those who are relatively effective using social skills and consequently can make friends, who are able to communicate their ideas to others, to get involved in pretend play activities, who comply with the rules and demonstrate an interest in the peer interaction showing an understanding of their actions (Odom, Zercher, et al., 2007).

Regarding peer culture we can observe two situations. The study by Odom,, et al. (2007) shows that there are peers of children with SN who try to find common interests, that may allow communication and joint performance of play activities. There are also situations in which children are excluded from the peer culture, because they are simply ignored, or because the peers fail to understand the behaviors of the child, during the course of the activities (Odom, Zercher, et al., 2007). 
The peers without SN exhibit, from the outset, a greater social competence, which leads them to have a leading role in the interactions with children with SN, since they can assume an active control over the organization and performance of play activities, which, in turn, leads them to assume, often, a routing or tutorial role (Beckman \& Lieber, 1992) This role results from the tendency to perceive peers with $\mathrm{SN}$ as more dependant. Because the child seems more fragile than the other playmates, their peers tend to render him/her infantile, by choosing, frequently, to themselves a helping or protective role, which could be a negative factor, given the likelihood of giving more help than the child with SN would actually require (Odom, Zercher, et al., 2007).

\section{Final considerations}

Literature emphasizes the importance of peer relations for the development and mastery of social competence in increasingly challenging and unprotected situations. It is also clear the greater role attributed to all elements and aspects of the context, concerning child's development.

As though, research specifically focused on the strengthening of social competence in peer relations of children with SN would probably help us find new answers and/or new ways of approaching the different aspects of the context, which would, probably, entail positive consequences at the level of the assessment, intervention and skills generalization.

\section{References}

Bandura, A. (1977). Social learning theory. New Jersey: Prentice - Hall.

Bandura, A. (1989). Social cognitive theory. In R. Vasta (Ed.), Annals of child development: Six theories of child development (Vol. 6, pp. 1-60). Greenwich: JAI Press.

Beckman, P. J., \& Lieber, J. (1992). Parent - child social relationships and peer social competence of preschool children with disabilities. In S. L. Odom, S. R. McConnell \& M. A. McEvoy (Eds.), Social competence of young children with disabilities: Issues and strategies for intervention (pp. 65 - 92). Baltimore: Paul H. Brookes Publishing Co. . 
Bracken, S. S., \& Fischel, J. E. (2007). Relationships between social skills, behavioral problems, and school readiness for Head Start children. NHSA Dialog, 10(2), $109-126$

Bronfenbrenner, U. (1975). The ecology of human development in retrospect and prospect. Paper presented at the Conference on ecological factors in human development.

Bronfenbrenner, U. (1986). Ecology of the family as a context for human development: Research perspectives. Developmental Psychology, 22(6), 723 - 742.

Bronfenbrenner, U. (1999). Environments in developmental perspective: Theoretical and operational models. In S. L. Friedman \& T. D. Wachs (Eds.), Measuring environment across life span: Emerging methods and concepts (pp. 3-38). Washington DC: American Psychological Association Press.

Brown, A. L., Metz, K. E., \& Campione, J. C. (1996). Social interaction and individual understanding in a community of learners: The influence of Piaget and Vygotsky. In A. Tryphon \& J. Vonèche (Eds.), Piaget - Vygotsky: The social genesis of thought (pp. 145 - 170). Hove: Psychology Press.

Brown, W. H., Odom, S. L., \& Conroy, M. A. (2001). An intervention hierarchy for promoting young children's peer interactions in natural environments. Topics in Early Childhood Special Education, 162 -175

Brown, W. H., Odom, S. L., McConnell, S. R., \& Rathel, J. M. (2008). Peer interaction interventions for preeschool children with developmental difficulties. In W. H. Brown, S. L. Odom \& S. R. McConnell (Eds.), Social competence of young children: Risk, disability and intervention (pp. 141-163). London: Paul H. Brookes Publishing Co.

Chapman, T. L. S.-., \& Snell, M. E. (2011). Promoting turn - taking skills in preschool children with disabilities. The effects of peer based social communication intervention. . Early Childhood Research Quarterly, 26, 303 - 319.

Chen, X., \& French, D. C. (2008). Children's social competence in cultural context. Annu. Rev. Psychol., 59, 591 - 616.

Corsaro, W. A. (1993). Friendship and peer culture in the early years. New Jersey: Ablex Publishing Corporation

Corsaro, W. A., \& Eder, D. (1990). Children's peer cultures. Annu Rev Sociol, 16, 197220. 
Crick, N. R., \& Dodge, K. A. (1994). A review and reformulation of social informationprocessing mechanisms in children's social adjustment. Psychological Bulletin, 115(1), 74-101.

Denham, S. A., Blair, K. A., DeMulder, E., Levitas, J., Sawyer, K., Major, S. A.-., et al. (2003). Preeschool emotional competence: Pathway to social competence? Child Development, 74(1), 238-256.

Diamond, K. E., Hong, S. Y., \& Baroody, A. E. (2008). Promoting young children's social competence in early childhood programs In W. H. Brown, S. L. Odom \& S. R. McConnell (Eds.), Social competence of young children: Risk, disability and intervention (pp. 165-184). London: Paul H. Brookes Publishing Co.

Dunst, C. J., Trivette, C. M., Raab, M., \& Masiello, T. L. (2008). Early child contingency learning and detection: Research evidence and implications for practice. Exceptionality, 16(4), 4 - 17.

Eisenberg, N., Spinrad, T. L., \& Eggum, N. D. (2010). Emotion-related self-regulation and its relation to children's maladjustment. Annual Review of Clinical Psychology, 6, 495 - 525.

Fleer, M., Anning, A., \& Cullen, J. (2004). A framework for conceptualising early childhood education. In A. Anning, J. Cullen \& M. Fleer (Eds.), Early childhood education. London: Sage Publications.

Furman, L. N., \& Walden, T. A. (1990). Effect of script knowledge on preschool children's communicative interactions. Developmental Psychology, 26(1).

Garbarino, J., \& Ganzel, B. (2000). The human ecology of early risk In J. P. Shonkoff \& S. J. Meisels (Eds.), Handbook of early childhood intervention (2nd ed., pp. 76 - 93). Cambridge: Cambridge University Press.

Guralnick, M. J. (1992). A hierarchical model for understanding children's peer - related social competence In S. L. Odom, S. R. McConnell \& M. A. McEvoy (Eds.), Social competence of young children with disabilities: Issues and strategies for intervention (pp. 37 - 64). Baltimore: Paul H. Brookes Publishing.

Guralnick, M. J. (1999). Family and child influences on the peer - related social competence of young children with developmental delays. Mental Retardation and Developmental Disabilities Research Reviews (5), 21 - 29 
Guralnick, M. J. (2006a). Family influences on early development: Integrating the science of normative development, risk and disability and intervention. . In K. McCartney \& D. Phillips (Eds.), Handbook of early childhood development (pp. 44-61). Oxford: Blackell Publishers.

Guralnick, M. J. (2006b). Peer relationships and the mental health of young children with intellectual delays Journal of Policy and Practice in Intellectual Disabilities, 3(1), 49-56.

Guralnick, M. J. (2010). Early intervention approaches to enhance the peer-related social competence of young children with developmental delays: A historical perspective. Infants \& Young Children, 23(2), 73-83.

Guralnick, M. J. (2011). Early intervention approaches to enhance the peer-related social competence of young children with developmental delays: A historical perspective. Infants \& Young Children, 23, 73-83.

Guralnick, M. J., Connor, R. T., Hammond, M. A., Gottman, J. M., \& Kinnish, K. (1996). The peer relations of preschool children with communication disorders. Child Development, 67(2), 471-489.

Guralnick, M. J., Connor, R. T., Neville, B., \& Hammond, M. A. (2006). Promoting the peer-related social development of young children with mild developmental delays: Effectiveness of a comprehensive intervention. American Journal on Mental Retardation, 111(5), 336 - 356

Guralnick, M. J., Hammond, M. A., \& Connor, R. T. (2006). Nonsocial play patterns of young children with communication disorders: Implications for behavioral adaptation. Early Education and Development, 17(2), 203 - 228

Guralnick, M. J., Hammond, M. A., Connor, R. T., \& Neville, B. (2006). Stability, change, and correlates of the peer relationships of young children with mild developmental delays. Child Development, 77(2), 312-324.

Hanson, M. J. (2007). Diversidade cultural e linguística: Influências na inclusão préescolar. In S. L. Odom (Ed.), Alargando a roda: A inclusão de crianças com necessidades educativas especiais na educação pré-escolar (pp. 117 - 130). Porto: Porto Editora

Hartup, W. (2009). Critical issues and theoretical viewpoints. In K. H. Rubin, W. M. Bukowski \& B. Laursen (Eds.), Handbook of peer interactions, relationships, and groups (pp. 3 - 19). New York: The Gildford Press. 
Lefrançois, G. R. (1995). Theories of human learning: Kro's report (3rd ed.). London: Brooks/Cole Publishing Company.

Lemerise, E. A., \& Arsenio, W. F. (2000). An integrated model of emotion processes and cognition in social information processing. Child Development, 71(1), 107 118.

MacNaughton, G. (2004). Exploring critical constructivist perspectives on children's learning In A. Anning, J. Cullen \& M. Fleer (Eds.), Early childhood education. London: Sage Publications.

Mahoney, G., \& Nam, S. (2011). The parenting model of intervention. In R. M. Hodapp (Ed.), International review of research in developmental disabilties. London: Elsevier.

Manz, P. H., \& McWayne, C. M. (2004). Early interventions to improve peer relations/social competence of low-income children. Encyclopedia on Early Childhood Development, 1-7. Retrieved from http://www.childencyclopedia.com/documents/Manz-McWayneANGxp.pdf

Martí, E. (1996). Mechanisms of internalisation and externalisation of knowledge in Piaget's and Vygotsky's theories. In A. Tryphon \& J. Vonèche (Eds.), Piaget Vygotsky: The social genesis of thought (pp. 57 - 83). Hove: Psychology Press.

McCollum, J. A., \& Ostrosky, M. M. (2008). Family roles in young children's emerging peer-related social competence. In W. H. Brown, S. L. Odom \& S. R. McConnell (Eds.), Social competence of young children: Risk, disability and intervention (pp. 31-59). London: Paul H. Brookes Publishing Co. .

McEvoy, M. A., Odom, S. L., \& McConnell, S. R. (1992). Peer social competence intervention for young children with disabilities. In S. L. Odom, S. R. McConnel \& M. A. McEvoy (Eds.), Social competence of young children with disabilities: Issues and strategies for intervention (pp. 113 - 133). Baltimore: Paul H. Brookes Publishing Co.

Meisels, S. J., \& Burnett, S. A.-. (2000). The elements of early childhood assessment. In J. P. Shonkoff \& S. J. Meisels (Eds.), Handbook of early childhood intervention (2nd ed., pp. 231 - 257). Cambridge: Cambridge University Press. 
Missall, K. N., \& Hojnoski, R. L. (2008). The critical nature of young children's emerging peer-related social competence for transition to school In S. L. O. William H. Brown, Scott R. McConnell (Ed.), Social competence of young children - Risk, disability \& intervention. Baltimore: Paul H. Brookes.

Odom, S. L. (2005). Peer-related social competence for young children with disabilities Encyclopedia on Early Childhood Development. Retrieved from http://www.child-encyclopedia.com/documents/OdomANGxp.pdf

Odom, S. L., Brown, W. H., Schwartz, I. S., Zercher, C., \& Sandall, S. R. (2007). Ecologia da sala e participação da criança. In S. L. Odom (Ed.), Alargando a roda: A inclusão de crianças com necessidades educativas especiais na educação pré-escolar (pp. 27 - 43). Porto: Porto Editora

Odom, S. L., McConnel, S. R., \& Brown, W. H. (2008). Social competence of young children: Conceptualization, assessment and influences. In W. H. Brown, S. L. Odom \& S. R. McConnell (Eds.), Social competence of young children: Risk, disability \& intervention (pp. 3-29). London: Paul H. Brookes Publishing Co. .

Odom, S. L., McConnel, S. R., \& McEvoy, M. A. (1992). Peer-related social competence and its significance for young children with disabilities. In S. L. Odom, S. R. McConnel \& M. A. McEvoy (Eds.), Social competence of young children with disabilities: Issues and strategies for intervention (pp. 3-35). Baltimore: Paul H. Brookes Publishing Co.

Odom, S. L., Zercher, C., Marquart, J., Li, S., Sandall, S. R., \& Wolfberg, P. (2007). Relações sociais entre crianças com NEE e os seus colegas. In S. L. Odom (Ed.), Alargando a roda: A inclusão de crianças com necessidades educativas especiais na educação pré-escolar (pp. 57 - 72). Porto: Porto Editora.

Portugal, G. (1992). Ecologia e desenvolvimento humano em Bronfenbrenner. Aveiro: CIDInE.

Rantala, A., Uotinen, S., \& McWilliam, R. A. (2009). Providing early intervention within natural environments: A cross-cultural comparison. Infants \& Young Children, 22(2), 119 - 131.

Richmond, P. G. (1970). An introduction to Piaget. London: Routledge \& Kegan Paul. 
Sainato, D. M., Jung, S., Salmon, M. D., \& Axe, J. B. (2008). Classroom influences on young children's emerging social competence. In W. H. Brown, S. L. Odom \& S. R. McConnell (Eds.), Social Competence of Young Children - Risk, Disability \& Intervention. Baltimore: Paul H. Brookes.

Sameroff, A. J., \& Fiese, B. H. (2000). Transactional regulation: The developmental ecology of early intervention. In J. P. Shonkoff \& S. J. Meisels (Eds.), Handbook of early childhood intervention (2nd ed., pp. 135 - 159). Cambridge: Cambridge University Press.

Sameroff, A. J., \& Mackenzie, M. J. (2003). Research strategies for capturing transactional models of development: The limits of the possible. Development and Psychopathology, 15, 613-640.

Schneider, N., \& Goldstein, H. (2008). Peer - related social competence interventions for young children with communication and language disorders. In S. L. O. William H. Brown, Scott R. McConnel (Ed.), Social competence of young children - risk, disability \& intervention. Baltimore: Paul H. Brookes.

Siraj-Blatchford, I. (2004). Quality teaching in the early years. In A. Anning, J. Cullen \& M. Fleer (Eds.), Early childhood education. London: Sage Publications.

Tanta, K. J., Deitz, J. C., White, O., \& Billingsley, F. (2005). The effects of peer-play level on initiations and responses of preschool children with delayed play skills. The American Journal of Occupational Therapy 59(4), 437 - 445.

Tomasello, M. (2000). The cultural origins of human cognition. Londres: Harvard University Press.

Tomasello, M. (2003). Constructing a language: A usage-based theory of language acquisition. London: Harvard University Press.

Tomasello, M., \& Carpenter, M. (2007). Shared intentionality. Developmental Science, 10(1), 121-125.

Tryphon, A., \& Vonèche, J. (1996). Introduction. In A. Tryphon \& J. Vonèche (Eds.), Piaget - Vygotsky: The social genesis of thought (pp. 1 - 10). Hove: Psychology Press.

Vygotsky, L. (1978). Interaction between learning and development. In M. Cole, V. J.-. Steiner, S. Sribner \& E. Souberman (Eds.), Mind in Society: The development of higher psychological processes. London: University Press. 
Vygotsky, L. (1994). The problem of the environment. In R. V. D. Veer \& J. Valsiner (Eds.), The Vygotsky reader (pp. 338-354). Oxford: Blackwell.

Wertsch, J. V., \& Tulviste, P. (1996). L. S. Vygotsky and contemporary developmental psychology. In H. Daniels (Ed.), An introduction to Vygotsky (pp. 2). London: Routledge.

Wozniak, R. H. (1996). Qu'est-ce que l'intelligence? Piaget, Vygotsky, and the 1920s crisis in psychology. In A. Tryphon \& J. Vonèche (Eds.), Piaget - Vygotsky: The social genesis of thought (pp. 11 - 24). Hove: Psychology Press. 